\title{
GERAKAN ISI PIRINGKU PENUHI GIZI SEHAT DAN SEIMBANG ANAK USIA DINI DI DESA TELLUMPANUAE KABUPATEN MAROS
}

\author{
Hilmi Hambali ${ }^{*}$ \\ Wira Yustika Rukman² \\ Muh. Wajdi ${ }^{3}$ \\ Uyunnasirah Hambali ${ }^{4}$ \\ 1,2,3,4Universitas Muhammadiyah Makassar \\ hilmihambali@unismuh.ac.id $1^{*}$ \\ wirayustika@unismuh.ac.id ${ }^{2)}$ \\ muh.wajdi@unismuh.ac.id $\left.{ }^{3}\right)$ \\ uyunhambali@unismuh.ac.id ${ }^{4}$
}

Kata Kunci:
[Gerakan isi
piring, Anak usia
dini]

Published by:

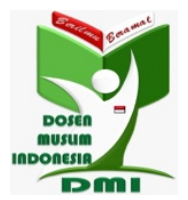

Copyright (C) 2021 The Author(s)

This article is licensed under CC BY 4.0 License

(cc) BY

https://dmi-journals.org/jai

\begin{abstract}
Abstrak: Pengabdian kepada Masyarakat melalui Gerakan Isi Piringku dilaksanakan di Desa Tellumpanuae Kecamatan Mallawa Kabupaten Maros. Tujuan kegiatan ini adalah untuk soaialisasi masalah Kebutuhan gizi pada anak. Permasalahan mitra adalah (1) Pengetahuan para orang tua dan guru Pendidikan Anak usia Dini tentang kebutuhan gizi anak masih relatif rendah (2) Masih kurangnya pengetahuan dan keterampilan para orang tua atau guru Pendidikan Anak usia Dini dalam pengelolaan berbagai sumber bahan makanan yang ada (3) Para orang tua dan guru Pendidikan Anak usia Dini belum sepenuhnya termotivasi untuk berusaha memberikan edukasi terkait gizi yang sehat dan seimbang untuk anak (4) Terbatasnya variasi jenis sayur dan buah di desa. Metode pengabdian masyarakat ini adalah 1) tahap persiapan, meliputi observasi langsung ke lokasi di TK Negeri 11 Pusat PAUD Al Tajri, 2) tahap pelaksanaan meliputi kegiatan penyuluhan gizi dan pemeriksaan golongan darah dan 3) tahap pelaporan. Kegiatan ini berdampak mendukung program pemerintah dalam hal ini kementrian kesehatan dalam mengatasi stunting dan kurang gizi pada anak. Dengan gerakan "Isi Piringku" masyarakat akan memiliki pengetahuan tentang kebutuhan gizi.
\end{abstract}




\section{Pendahuluan}

TK Negeri 11 Pusat PAUD Al Tajri terletak di Dusun Matajang Desa Tellumpanuae Kecamatan Mallawa Kabupaten Maros. Sekolah ini terletak di dataran tinggi. Akses ke sekolah terbilang baik sebab fasilitas seperti jalanan baru saja selesai diperbaiki. Hanya saja karena terletak di desa maka masyarakat tidak bisa menikmati pasar setiap hari, pasar di desa hanya tersedia di hari senin dan kamis. Hal inilah yang mempengaruhi masyarakat sekitar terbatas dalam hal variasi jenis makanan termasuk sayur dan buah, sehingga sangat mempengaruhi menu sehari-hari keluarga. Selain itu, letak geografis dan sumber daya alam yang tersedia jenisnya juga terbatas. Masyarakat terbiasa mengkonsumsi sayur dan buah yang itu-itu saja. Oleh karena itu, banyak anak-anak dan masyarakat yang kurang terpenuhi gizinya secara seimbang. Kondisi tersebut sangat mempengaruhi pola kebiasaan makan dan gizi pada masyarakatnya. Terutama pada anak usia dini yang seharusnya membutuhkan gizi yang sehat dan seimbang.

Perkembangan masalah gizi di Indonesia sendiri dikelompokkan menjadi tiga, yaitu masalah gizi yang sudah terkendali, masalah yang belum dapat terselesaikan (unfinished), dan masalah gizi yang sudah meningkat dan megancam kesehatan masyarakat (emerging). Untuk kegiatan pengabdian ini difokuskan pada masalah gizi yang belum dapat terselesaikan.

Berdasarkan data tahun 2013 sebanyak 37,2 persen balita di Indonesia mengalami stunting. Kondisi ini seringkali dianggap normal karena alasan keturunan. Padahal stunting dapat mempengaruhi perkembangan otak, mengurangi produktivitas serta banyak masalah kesehatan lainnya dikemudian hari. Oleh karena itu, pemahaman terkait gizi perlu selalu diberikan dan dioptimalisasikan kepada orang tua atau guru ataupun kepada anak-anak usia dini agar lebih memperhatikan masalah status dan kebutuhan gizi pada anak. Sehingga kegiatan sosialisasi baik berupa penyuluhan atau seminar kesehatan terkait masalah gizi perlu digalakkan seperti gerakan " isi piringku” yang merupakan jargon baru dari Kementrian Kesehatan yang mengganti istilah empat sehat lima sempurna. Gerakan 'isi piringku" adalah suatu kegiatan penyuluhan terkait pemenuhan gizi sehat dan seimbang pada anak, sebab setiap orang memiliki kebutuhan akan gizi yang berbeda-beda.

\section{Metode Pelaksanaan}

Upaya yang dilakukan untuk mengatasi masalah mitra adalah dengan melakukan Penyuluhan gizi dan kesehatan. Adapun langkah-langkah yang dilakukan adalah:

a. Tahap Persiapan

Dimulai dari observasi dan komunikasi kepada pihak sekolah dalam hal ini sekolah mitra dan pihak kecamatan untuk mengurus surat izin pelaksanaan kegiatan.

b. Tahap Pelaksanaan

Pada tahap ini meliputi proses penyuluhan terkait gizi dan kesehatan. Dimana para peserta yang terdiri dari orang tua dan anak dikumpulkan dalam suatu tempat/aula atau ruangan untuk mengikuti pemaparan materi dan setelahnya dirangkaikan dengan kegiatan pemeriksaan kesehatan berupa pemeriksaan golongan darah dan pemeriksaan glukosa darah. 
c. Tahap Pelaporan

Menyusun hasil kegiatan dalam bentuk laporan dan proses penerbitan jurnal.

\section{Hasil dan Pembahasan}

Kegiatan ini dimulai dengan pembukaan serta sambutan dari pihak sekolah yang sangat memberikan apresiasi terhadap kehadiran tim di sekolahnya untuk menyampaikan materi tentang Gizi pada orang tua dan siswa. Kepala sekolah sangat mengharapkan kagiatan pengabdian masyarakat ini sendiri tidak berhenti sampai pada kegiatan penyuluhan saja.

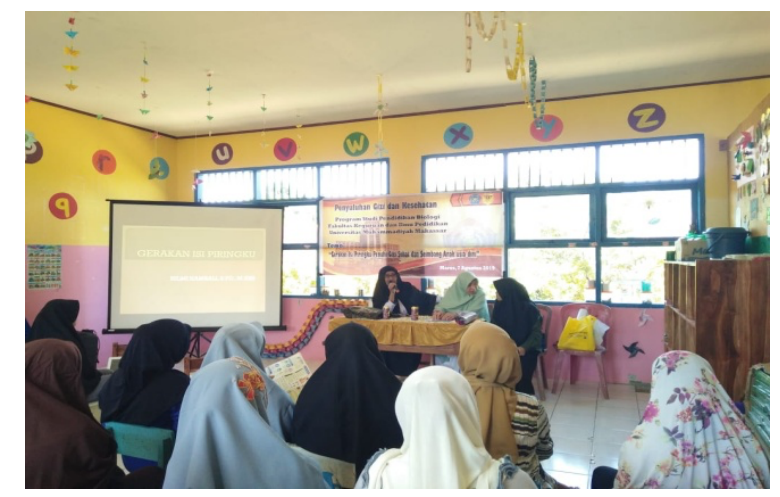

Gambar 1. Pembukaan dan sambutan Kepala Sekolah

Pelaksanaan kegiatan ini berlangsung selama satu hari, dimulai dari penyampaian materi oleh pemateri dalam hal ini ketua tim yaitu Hilmi Hambali, S.Pd.,M.Kes. Materi yang disampaikan adalah terkait penjelasan apa itu isi piringku dan bagaimana agar anak-anak di usia dini mendapatkan makanan yang sehat, bergizi dan seimbang mulai dari rumah, agar anak-anak terpenuhi gizinya dan dapat mencegah anak dari stunting .

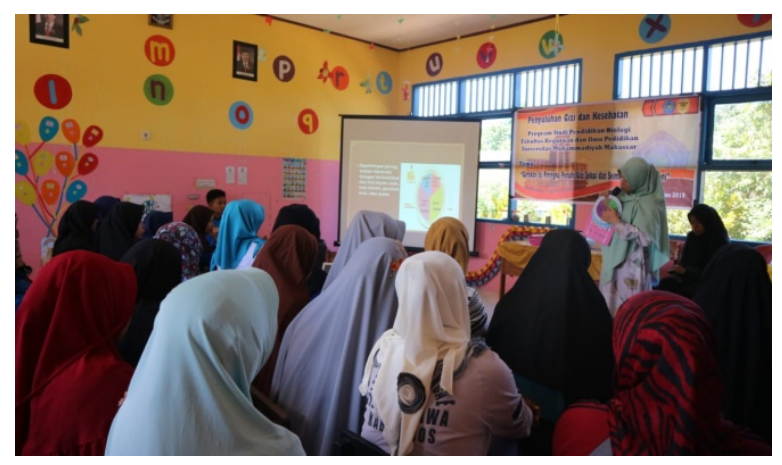

Gambar 2. Pemaparan materi

Pada saat penyampaian materi juga berlangsung proses diskusi melalui Tanya jawab oleh peserta dan pemateri terkait dengan masalah gizi pada anak. 


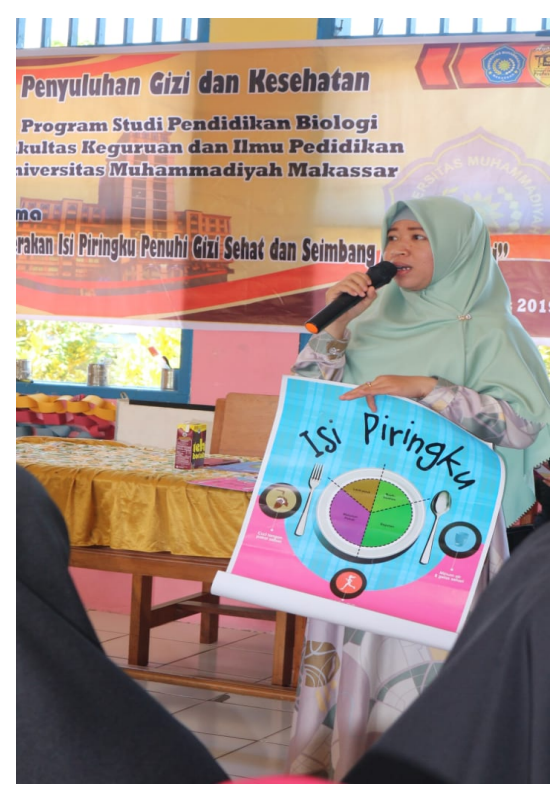

Gambar 3. Memperlihatkan poster isi piringku

Setelah penyampaian materi selesai, maka kegiatan dilanjutkan dengan pemeriksaan kesehatan gratis yaitu pemeriksaan tekanan darah dan glukosa darah bagi orang tua siswa dan pemeriksaan golongan darah bagi siswa

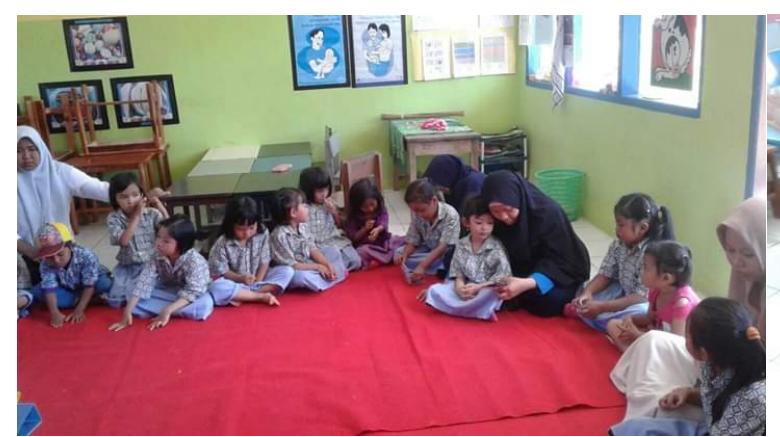

Gambar 4. Persiapan pemeriksaan darah

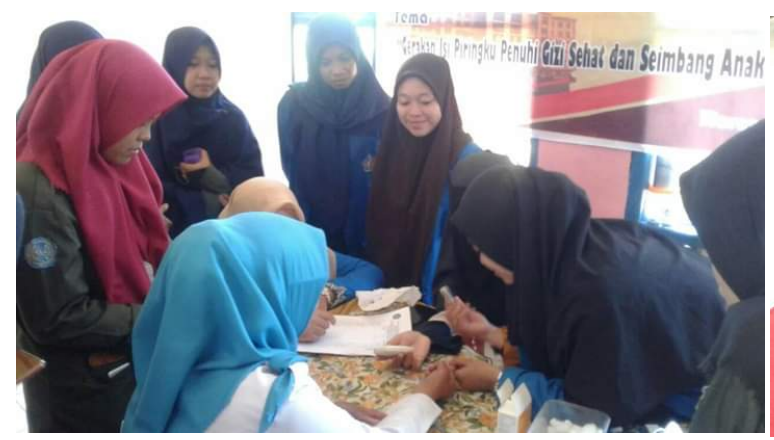

Gambar 6. Pemeriksaan glukosa darah

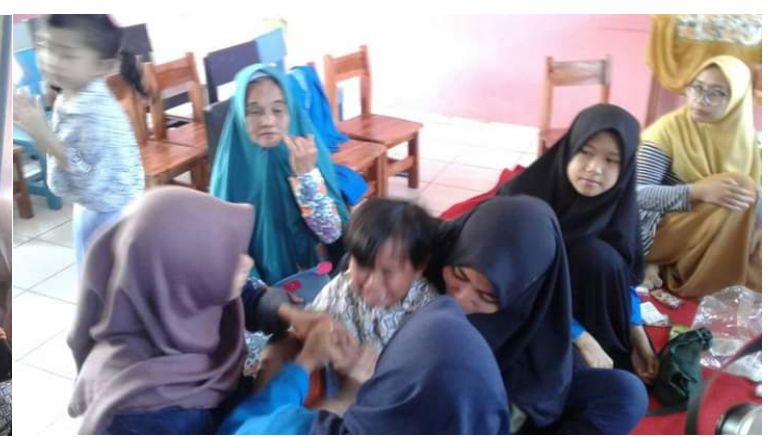

Gambar 5. Pemeriksaan Golongan darah pada siswa

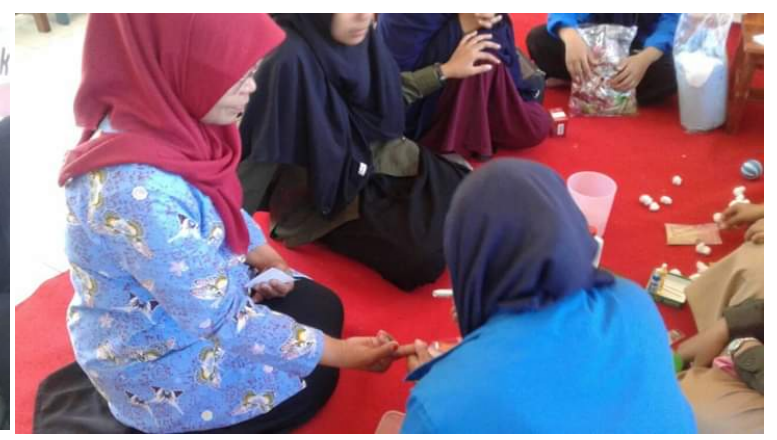

Gambar 7. Pemeriksaan glukosa darah

Kampanye Isi Piringku merupakan salah satu solusi cerdas untuk mengatasi stunting di Tanah Air. Melalui kampanye Isi Piringku, kita bisa meretas pencegahan stunting di daerah masing-masing. Berpartispasi aktif dalam pencegahan stunting berarti telah memberi kontribusi secara langsung dalam mewujudkan Indonesia sehat. Stunting adalah masalah kurang gizi kronis yang ditandai tinggi badan anak lebih rendah dari standar usianya dan keterlambatan fungsi otak. Kondisi ini diakibatkan kurangnya 
asupan gizi dalam waktu cukup lama sebagai dampak dari pemerian makanan yang tidak sesuai dengan kebutuhan gizi. Stunting terjadi mulai dalam kandungan dan baru terlihat pengaruhnya ketika balita berusia dua tahun. Oleh karena itu, penyuluhan terkait masalah gizi harus terus dilakukan agar menjadi upaya pencegahan.

\section{Kesimpulan}

Kegiatan sosialisasi atau penyuluhan tentang gizi dan kesehatan sangat perlu dilakukan untuk mendukung program pemerintah dalam hal ini kementrian kesehatan dalam mengatasi stunting dan kurang gizi pada anak. Dengan gerakan "Isi Piringku" masyarakat akan memiliki pengetahuan tentang kebutuhan gizi terutama untuk anak.

Gerakan isi piringku sebaiknya rutin dilakukan di sekolah-sekolah atau di kelompok masyarakat agar pemahaman tentang gizi meningkat. Dan perlu ditambahkan kegiatan pendampingan bagi orang tua khususnya ibu dalam menyiapkan menu makanan untuk anggota keluarga.

\section{Ucapan Terimakasih}

Penulis mengucapkan terima kasih kepada LP3M Universitas Muhammadiyah Makassar yang memberikan pendanaan untuk kegiatan pengabian kepada masyarakat ini. Terima kasih juga untuk mitra yaitu TK Al Tajri Desa Tellumpanuae Maros atas kesediaannya bekerjasama dengan kami.

\section{Referensi}

Dahlan, Sopiyudin. 2017. Statistik untuk Kedokteran dan Kesehatan. Salemba Medika. Jakarta

Djaeni, Achmad. 2016. Ilmu Gizi untuk Mahasiswa dan Profesi Jilid 1. Dian Rakyat. Jakarta

Djaeni, Achmad. 2016. Ilmu Gizi untuk Mahasiswa dan Profesi Jilid 2. Dian Rakyat. Jakarta

Soekirman,2013. Ilmu Gizi dan Aplikasinya. Dirjen Pendidikan Tinggi Departemen Pendidikan Nasional. Jakarta 